\title{
Quantification of left ventricular remodeling in response to isolated aortic or mitral regurgitation
}

\author{
Seth Uretsky¹, Azhar Supariwala', Puspalatha Nidadovolu'1, Surinder S Khokhar ${ }^{1}$, Cindy Comeau², Oleg Shubayev², \\ Francesca Campanile² and Steven D Wolff2
}

\begin{abstract}
Background: The treatment of patients with aortic regurgitation (AR) or mitral regurgitation (MR) relies on the accurate assessment of the severity of the regurgitation as well as its effect on left ventricular (LV) size and function. Cardiovascular Magnetic Resonance (CMR) is an excellent tool for quantifying regurgitant volumes as well as LV size and function. The 2008 AHA/ACC management guidelines for the therapy of patients with AR or MR only describe LV size in terms of linear dimensions (i.e. end-diastolic and end-systolic dimension). LV volumes that correspond to these linear dimensions have not been published in the peer-reviewed literature. The purpose of this study is to determine the effect of regurgitant volume on LV volumes and chamber dimensions in patients with isolated AR or MR and preserved LV function.
\end{abstract}

Methods: Regurgitant volume, LV volume, mass, linear dimensions, and ejection fraction, were determined in 34 consecutive patients with isolated AR and 23 consecutive patients with MR and no other known cardiac disease.

Results: There is a strong, linear relationship between regurgitant volume and LV end-diastolic volume index (aortic regurgitation $r^{2}=0.8$, mitral regurgitation $r^{2}=0.8$ ). Bland-Altman analysis of regurgitant volume shows little interobserver variation (AR: $0.6 \pm 4 \mathrm{ml}$; MR $4 \pm 6 \mathrm{ml}$ ). The correlation is much poorer between regurgitant volume and commonly used clinical linear measures such as end-systolic dimension (mitral regurgitation $r^{2}=0.3$, aortic regurgitation $r^{2}=0.5$ ). For a given regurgitant volume, AR causes greater LV enlargement and hypertrophy than MR.

Conclusion: CMR is an accurate and robust technique for quantifying regurgitant volume in patients with AR or MR. Ventricular volumes show a stronger correlation with regurgitant volume than linear dimensions, suggesting LV volumes better reflect ventricular remodeling in patients with isolated mitral or aortic regurgitation. Ventricular volumes that correspond to published recommended linear dimensions are determined to guide the timing of surgical intervention.

\section{Introduction}

The timing of surgical intervention for patients with mitral or aortic regurgitation often depends on the accurate assessment of the severity of the valvular insufficiency and its effect on left ventricular (LV) size [1,2]. Two-dimensional transthoracic and transesophageal echocardiography are most commonly used to assess mitral and aortic regurgitation. Published guidelines recommend the use of LV ejection fraction as well as linear measurements such as LV end-diastolic dimension (EDD)

\footnotetext{
*Correspondence: suretsky@chpnet.org

1 Division of Cardiology, Department of Medicine, St. Luke's-Roosevelt Hospital Center, Columbia University College of Physicians and Surgeons, 1111 Amsterdam Avenue, New York, NY 10025, USA

Full list of author information is available at the end of the article
}

and LV end-systolic dimension (ESD) to determine the timing of surgical interventions [2]. Cardiovascular magnetic resonance (CMR) is an accurate method for quantifying the severity of mitral and aortic regurgitation [3-7]. CMR is more accurate and reproducible than two-dimensional echocardiography in the three-dimensional volumetric evaluation of LV size and function [8-14]. An important limitation of the current guidelines is that no volumetric parameters are provided for determining the timing of surgery and we currently rely on linear measurements as a surrogate for describing LV volumetric changes. The purpose of this study is to characterize the physiological relationship between regurgitant volume 
and LV volume with CMR in patients with mitral and aortic regurgitation.

\section{Methods}

\section{Patient characteristics}

This study was a retrospective analysis of patients referred for a clinical CMR evaluation between 2006 and 2009. This study was approved by the Institutional Review Board of St. Luke's and Roosevelt Hospitals. Consecutive patients were included provided 1) they had sufficient mitral or aortic regurgitation to warrant quantification of their regurgitant volume in their clinical report and 2) phase contrast images of pulmonary artery and aortic flow were acquired with a corresponding phantom image for correcting baseline flow offsets [15]. Patients whose CMR studies showed other significant cardiac abnormalities were excluded. Exclusion criteria included: more than mildly abnormal ventricular function ( $\mathrm{LVEF}<50 \%$ or right ventricular $\mathrm{EF}<40 \%$ ), regional ventricular wall motion abnormalities, more than right ventricular (RV) enlargement (RV end-diastolic volume index $>115 \mathrm{ml} / \mathrm{m}^{2}$ ), myocardial ischemia or scar, left ventricular hypertrophy, intracardiac shunt, more than mild tricuspid or pulmonic regurgitation, and patients with an irregular cardiac rhythm. Additionally, patients were excluded from the mitral regurgitation (MR) group if they had more than minimal $(>10 \mathrm{ml})$ aortic regurgitation (AR) and from the AR group if they had more than minimal $(>10 \mathrm{ml}) \mathrm{MR}$. The analysis comprised 57 patients who underwent CMR evaluation, and included 34 patients $(62 \pm 17$ years, male $88 \%)$ with $\mathrm{AR}$ and 23 patients $(55 \pm 15$ years, male $65 \%)$ with MR.

\section{CMR image acquisition}

Patients were imaged with a 1.5-Tesla scanner using an 8element, phased-array coil (GE Signa, EXCITE, GE Medical Systems, Milwaukee, Wisconsin, USA). Images were acquired with ECG gating and breath holding. Short and long axis cine images were acquired using a steady-state free precession pulse sequence (FIESTA) with the following parameters: TR/TE $3.3 \mathrm{~ms} / 1.4 \mathrm{~ms}, 20$ views per segment, FOV $35 \times 35 \mathrm{~cm}$, acquisition matrix $192 \times 160$, slice thickness $8 \mathrm{~mm}$, slice gap $0 \mathrm{~mm}$, flip angle 45 degrees, receive bandwidth $125 \mathrm{kHz}$. Phase contrast images were acquired perpendicular to the proximal pulmonary artery and perpendicular to the proximal aorta to quantify flow in these vessels using the following parameters: TR/TE $7.5 \mathrm{~ms} / 2.9 \mathrm{~ms}, 6$ views per segment, Venc $250 \mathrm{~cm} / \mathrm{s}$, FOV $35 \times 35 \mathrm{~cm}$, acquisition matrix $256 \times 128$, slice thickness $4 \mathrm{~mm}$, flip angle 20 degrees, receive bandwidth $31.3 \mathrm{kHz}$. After the clinical scan was completed, additional phase contrast images were acquired of a stationary bottle of water (phantom) for baseline flow correction [15].

\section{CMR image analysis}

Images were reviewed and analyzed using ReportCard 4.0 software. LV volumes and mass were determined using the semiautomated LV segmentation algorithm which excludes papillary muscles and trabeculations from the LV cavity and which uses a long axis image to define the position of the LV base. RV volumes were determined by manual segmentation of the short axis images. Aortic and pulmonary artery flow values were determined using the resident semiautomated algorithm. Correction for baseline offsets was performed using a phantom phase contrast image as described previously [15]. In some patients two or three flow acquisitions were made. In these cases, the flow values were averaged. Aortic regurgitant volume was determined by integrating blood flow throughout diastole. Aortic and mitral regurgitant volume were defined as per the AHA/ACC treatment guidelines: mild $<30 \mathrm{ml}$, moderate $30-59 \mathrm{ml}$, and severe $\geq 60 \mathrm{ml}$. Mitral regurgitant volume was determined as the difference between the LV stroke volume (as determined by endocardial segmentation) and total pulmonary artery flow. Left atrial (LA) volumes were calculated using the arealength method ( $\mathrm{LV}$ volume $=0.85^{*} \mathrm{Area}^{2} /$ length) by averaging values from the four and two chamber views. To determine the reproducibility of AR and MR regurgitant volume, a second blinded analysis was made according to the same method.

\section{Statistical analysis}

All analyses were carried out using a standard statistical package (SPSS Version 16.0, SPSS Inc., Chicago, Illinois). Continuous variables were reported as mean \pm SD and categorical variables were reported as percentages. Correlation between regurgitant volumes and left ventricular measures and left atrial volumes were calculated using Pearson's correlation coefficient. Interobserver variability was measured using Bland-Altman analysis and Intraclass Correlation Coefficient. P values were considered significant at $<0.05$.

\section{Results}

\section{Aortic regurgitation}

Demographic and CMR data of the patients with AR are summarized in Table 1. Of the 34 patient studies with AR, 13 (38\%) have mild AR, 10 (30\%) have moderate AR, and $11(32 \%)$ have severe AR. The mean aortic regurgitant volume is $40 \pm 27 \mathrm{ml}$. The mean $\mathrm{LV}$ ejection fraction is 64 $\pm 7.5 \%$. For patients with mild, moderate or severe AR, the mean LV end-diastolic volume (EDVI) is $83 \pm 13 \mathrm{ml} /$ $\mathrm{m}^{2}\left(\right.$ range $\left.=61-100 \mathrm{ml} / \mathrm{m}^{2}\right), 103 \pm 13($ range $=82-121$ $\left.\mathrm{ml} / \mathrm{m}^{2}\right)$, and $146 \pm 19 \mathrm{ml} / \mathrm{m}^{2}\left(\right.$ range $\left.=125-186 \mathrm{ml} / \mathrm{m}^{2}\right)$ respectively. Figure 1 shows the relationships between regurgitant volume and LV end-diastolic volume index (EDVI), LV end-systolic volume index (ESVI), LV EDD, 


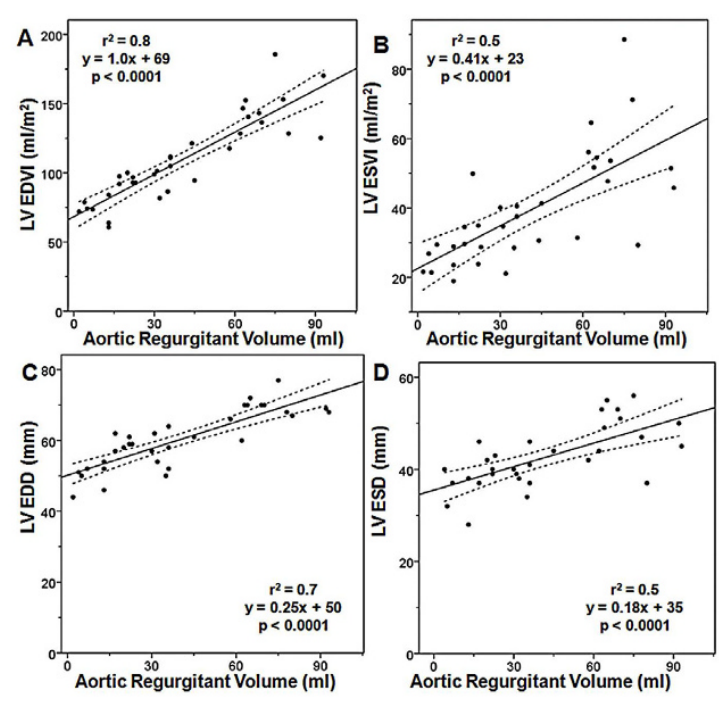

Figure 1 Relationship Between Aortic Regurgitant Volume and (A) LV EDVI, (B) LV ESVI, (C) LV EDD, and (D) LV ESD. EDD: end-diastolic dimension, EDVI: end-diastolic volume index, ESD: end-systolic dimension, ESVI: end-systolic volume index, LV: left ventricular.

and LV ESD. There is a strong, linear relationship between aortic regurgitant volume and LV EDVI $\left(r^{2}=\right.$ $0.8)$. There are moderate, linear relationships between aortic regurgitant volume and LV ESVI $\left(\mathrm{r}^{2}=0.5\right)$, LV EDD $\left(r^{2}=0.7\right)$, and LV ESD $\left(r^{2}=0.5\right)$. Linear regression is used to determine the $\mathrm{LV}$ volumes that correspond to an $\mathrm{LV}$ ESD of $55 \mathrm{~mm}$ and an LV EDD of $75 \mathrm{~mm}$. These values are listed in Table 2.

\section{Mitral regurgitation}

Demographic and CMR data of the patients with MR are summarized in Table 1 . Of the 23 patient studies with MR, 9 (40\%) have mild MR, 7 (30\%) have moderate MR, and $7(30 \%)$ have severe MR. The mean mitral regurgitant volume is $46 \pm 34 \mathrm{ml}$. The mean LV ejection fraction is 72 $\pm 6.4 \%$. For patients with mild, moderate or severe MR the mean LV EDVI is $75 \pm 10 \mathrm{ml} / \mathrm{m}^{2}$ (range $=62-89 \mathrm{ml} /$ $\left.\mathrm{m}^{2}\right), 94 \pm 8 \mathrm{ml} / \mathrm{m}^{2}\left(\right.$ range $\left.=82-107 \mathrm{ml} / \mathrm{m}^{2}\right)$ and $119 \pm 24$ $\mathrm{ml} / \mathrm{m}^{2}\left(\right.$ range $\left.=98-167 \mathrm{ml} / \mathrm{m}^{2}\right)$ respectively. Figure 2 shows the relationships between regurgitant volume and LV EDVI, LV ESVI, LV ESD, and LA volume. There is a strong, linear relationship between mitral regurgitant volume and LV EDVI $\left(r^{2}=0.8\right)$. There is a moderate, linear relationship between mitral regurgitant volume and LV ESVI $\left(r^{2}=0.5\right)$. There are weak linear relationships between mitral regurgitant volume and LV ESD $\left(r^{2}=0.3\right)$ and mitral regurgitant volume and LA volume $\left(\mathrm{r}^{2}=0.3\right)$. Linear regression is used to determine the LV volume that corresponds to an LV ESD of $40 \mathrm{~mm}$ (shown in Table 2).

\section{Interobserver agreement}

Figure 3 shows strong interobserver agreement in the quantification of AR. The mean \pm SD for aortic regurgitant volume was $39 \pm 26 \mathrm{ml}$ for observer 1 and $40 \pm 26 \mathrm{ml}$ for observer 2 with a strong correlation (Intraclass Correlation Coefficient $=0.99$ 95\% CI $0.989-0.997, \mathrm{p}<0.0001$ ). For aortic regurgitant volume, Bland-Altman analysis revealed a strong agreement between observer 1 and 2 with a mean difference of $0.6 \pm 4 \mathrm{ml}$ (95\% CI -8.52 to 7.32 sml). Figure 3 also shows strong interobserver agreement in the quantification of MR. The mean \pm SD for mitral regurgitant volume was $47 \pm 32 \mathrm{ml}$ for observer 1 and 43 $\pm 32 \mathrm{ml}$ for observer 2 with a strong correlation (Intraclass Correlation Coefficient $=0.99$ 95\% CI $0.95-0.99, \mathrm{p}<$ 0.0001). For mitral regurgitant volume, Bland-Altman analysis revealed a strong agreement between observer 1 and 2 with a mean difference of $4 \pm 6 \mathrm{ml}$ (95\% CI -9 to 17 $\mathrm{ml})$.

\section{The relationship of LV EDVI and mass index to the type and severity of regurgitation}

We found a greater increase in LV EDVI for a given regurgitant volume in patients with $\mathrm{AR}$ compared to those with MR (Figure 4). Furthermore, when comparing mean LV mass index among patients with moderate and severe regurgitation, those with AR had significantly higher LV mass index than those with MR (Figure 5). Mean LV mass index was significantly higher in patients with severe AR vs. mild AR $\left(118 \pm 22\right.$ vs. $77 \pm 17 \mathrm{~g} / \mathrm{m}^{2}, \mathrm{p}<$ $0.0001)$ and severe MR vs. mild MR ( $92 \pm 16$ vs. $65 \pm 20 \mathrm{~g} /$ $\left.\mathrm{m}^{2}, \mathrm{p}=0.01\right)$.

\section{Discussion}

CMR has long been accepted as an accurate and reproducible technique for evaluating LV size and function. Good correlation has been obtained by comparing CMR to other established techniques such as echocardiography $[11,16]$, contrast ventriculography [17], and radionuclide imaging $[18,19]$. In addition, several groups of investigators have documented the accuracy of CMR for quantifying regurgitant volumes in patients with $\mathrm{AR}$ or $\mathrm{MR}$, again by comparison to other imaging modalities such as echocardiography $[6,20-22]$ or cardiac catheterization [5]. A problem with these comparative studies is that it can be difficult to determine which of the two imaging modalities is correct when the results differ, which they inevitably do to at least some extent.

To our knowledge, this is the first CMR study to quantify the physiologic relationship between regurgitant volume and chamber volume in patients with isolated chronic AR or MR and preserved LV function. For both 
Table 1: Clinical and CMR data

\begin{tabular}{|c|c|c|}
\hline & Mitral Regurgitation $(n=23)$ & Aortic Regurgitation $(n=34)$ \\
\hline Age (years) & $55 \pm 15$ & $62 \pm 17$ \\
\hline Male sex & $15(65 \%)$ & $30(88 \%)$ \\
\hline Regurgitant volume (ml) & $46 \pm 34$ & $40 \pm 27$ \\
\hline LV EF (\%) & $72 \pm 6.4$ & $64 \pm 7.5$ \\
\hline LV ESD (mm) & $37 \pm 4.9$ & $42 \pm 6.7$ \\
\hline LV EDD (mm) & $58 \pm 5.8$ & $60 \pm 8.2$ \\
\hline LV EDV (ml) & $178 \pm 56$ & $215 \pm 67$ \\
\hline LV ESV (ml) & $49 \pm 18$ & $76 \pm 32$ \\
\hline LV EDVI ( $\mathrm{ml} / \mathrm{m} 2)$ & $94 \pm 23$ & $109 \pm 31$ \\
\hline LV ESVI (ml/m2) & $26 \pm 8.0$ & $39 \pm 16$ \\
\hline LV mass index (g/m2) & $79 \pm 21$ & $96 \pm 24$ \\
\hline RV EF (\%) & $58 \pm 8.4$ & $59 \pm 7.3$ \\
\hline RV EDV (ml) & $156 \pm 40$ & $156 \pm 43$ \\
\hline RV ESV (ml) & $67 \pm 30$ & $64 \pm 23$ \\
\hline RV EDVI ( $\mathrm{ml} / \mathrm{m} 2)$ & $80 \pm 16$ & $78 \pm 15$ \\
\hline RV ESVI (ml/m2) & $34 \pm 12$ & $33 \pm 10$ \\
\hline
\end{tabular}

Values are $\mathrm{n}(\%)$ or median \pm standard deviation.

EDD: end-diastolic dimension, EDV: end-diastolic volume, EDVI: end-diastolic volume index, EF: ejection fraction, ESD: end-systolic dimension,

ESV: end-systolic volume, ESVI: end-systolic volume index, LV: left ventricular, RV: right ventricle.

$\mathrm{AR}$ and $\mathrm{MR}$, we find a strong linear correlation between regurgitant volume and LV EDVI $\left(\mathrm{r}^{2}=0.8\right)$. This provides an independent line of evidence supporting the accuracy of MRI for quantifying regurgitant volume and ventricular volumes. We also find MRI is a robust technique. The data show excellent interobserver variation for quantifying regurgitant volume as demonstrated by the BlandAltman analysis which showed a mean difference of $0.6 \pm$ $4 \mathrm{ml}$ for AR and $4 \pm 6 \mathrm{ml}$ for MR.

In our patients with chronic mitral regurgitation, we find the correlation between regurgitant volume and LV
EDVI is stronger than with LV ESVI, probably in part because additional factors influence LV ESVI, such as myocardial contractility. The coupling between LV EDVI and regurgitant volume is strong. An $\mathrm{r}^{2}$ of 0.8 implies $80 \%$ of the observed variation in LV volume is due to the severity of the regurgitant volume. This implies that in our patient population only $20 \%$ of the variation is related to other factors such as differences in pre-load, afterload or heart rate. It is possible that an acute physiologic change could weaken the coupling between regurgitant volume and LV EDVI, because regurgitant volume is an

Table 2: Corresponding LV volumetric parameters to standard linear LV dimensions

\section{Mitral Regurgitation}

$E S D=40 \mathrm{~mm}$

ESVI: 29

ESV: 58

\section{Aortic Regurgitation}

$E S D=55 \mathrm{~mm}$ 


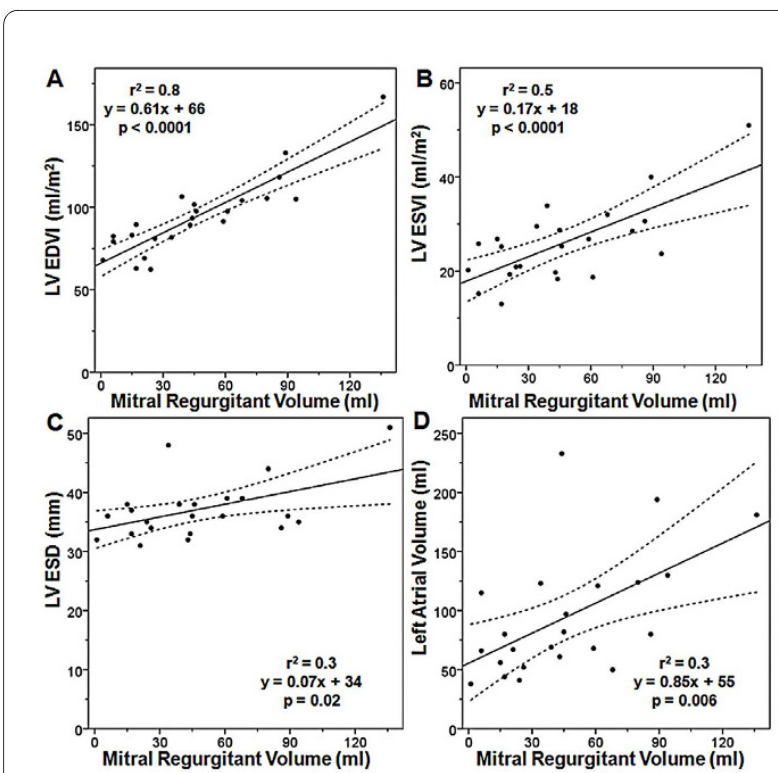

Figure 2 Relationship Between Mitral Regurgitant Volume and (A) LV EDVI, (B) LVESVI, (C) LV ESD, and (D) Left atrial volume. EDD: end-diastolic dimension, EDVI: end-diastolic volume index, ESVI: endsystolic volume index, LV: left ventricular.

instaneous measure whereas LV EDVI is a more chronic measure, and may better reflect the long term average severity of regurgitation. It is interesting to note that $\mathrm{LV}$ ESD, a parameter included in the AHA/ACC management guidelines to guide therapy, correlates very poorly with regurgitant volume $\left(\mathrm{r}^{2}=0.2\right)$. Finally, left atrial volume, a parameter which is often used by the echocardiographic community and which has been reported as a reliable estimator of regurgitant volume [23], shows a rel-

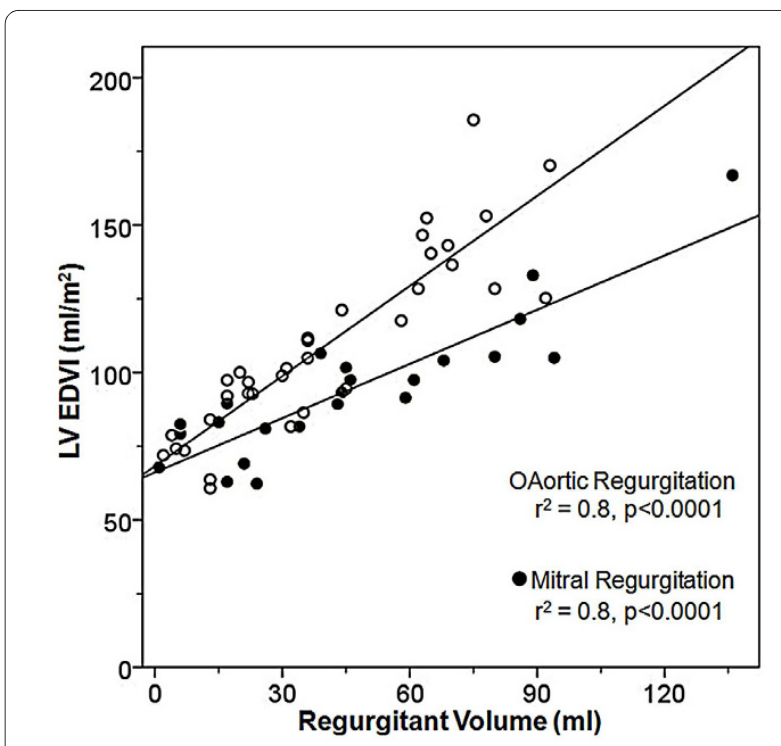

Figure 4 Relationship Between of Aortic and Mitral Regurgitant Volume and LV EDVI. EDVI: end-diastolic volume index, LV: left ventricular.

atively poor correlation with regurgitant volume $\left(\mathrm{r}^{2}=\right.$ $0.3)$.

In our patients with chronic $A R$, we find a stronger positive correlation with LV EDVI than with LV ESVI, again probably in part because additional factors influence LV ESVI, such as myocardial contractility. It is interesting to note that for a given regurgitant volume, patients with $A R$ have more LV enlargement and a greater LV mass index than patients with MR. This observation is likely due to the nature of the hemodynamic stress placed on the LV; whereas MR is a pure volume lesion AR is both a pressure
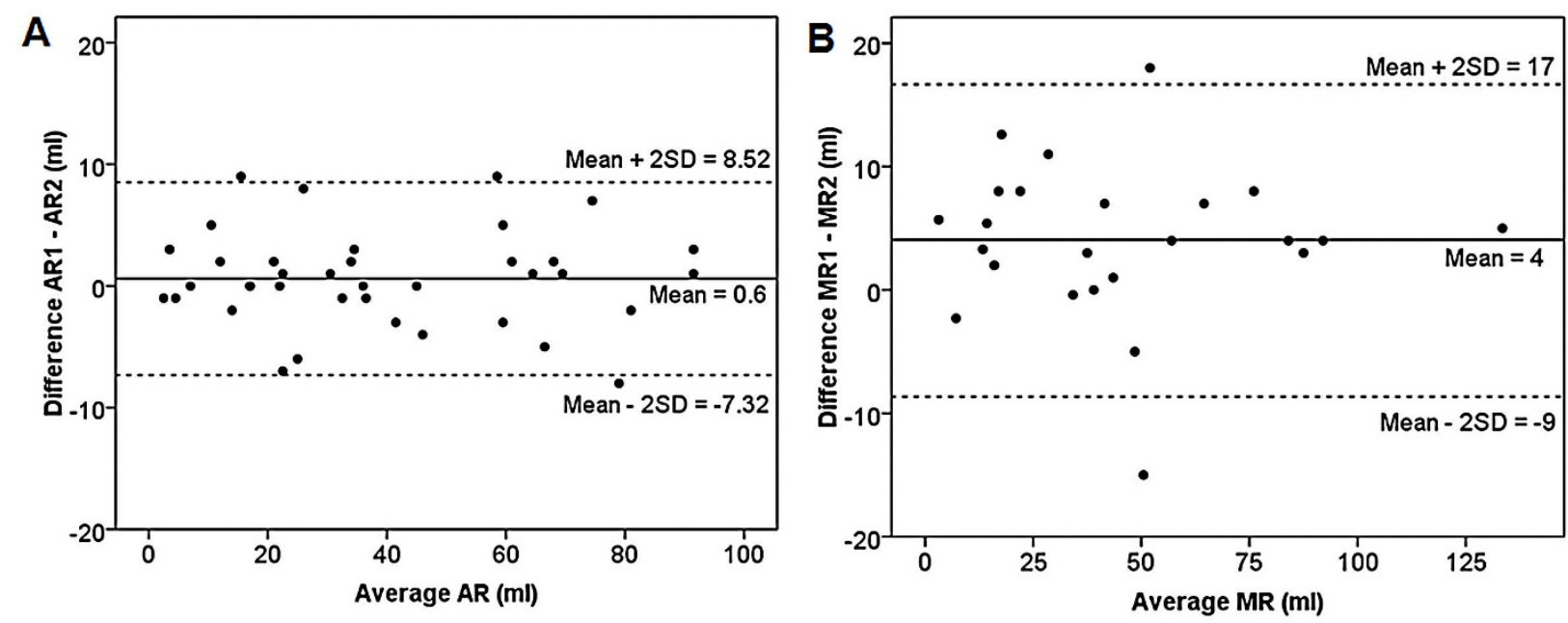

Figure 3 Bland-Altman analysis of the Interobsever Agreement for the Measure of (A) Aortic and (B) Mitral Regugitant Volume. AR: aortic regurgitation, MR: mitral regurgitation. 


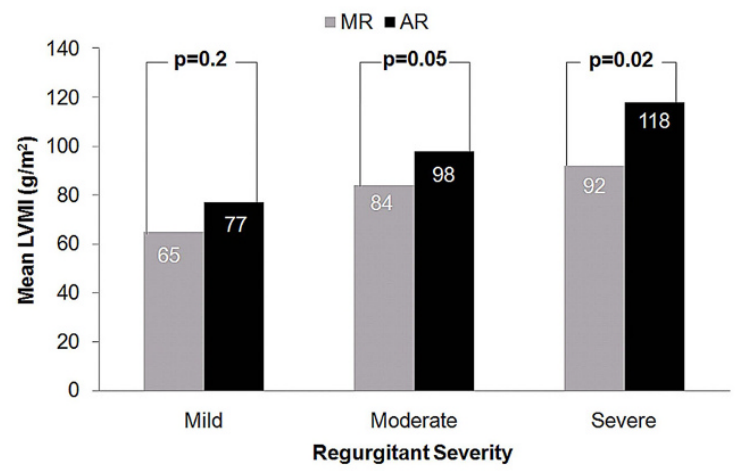

Figure 5 Comparison of mean LV mass index according the type of regurgitant lesion and the severity of the regurgitant lesion. AR: aortic regurgitation, LVMI: left ventricular mass index, MR: mitral regurgitation.

and a volume lesion [24]. Additionally, our data suggest that the difference between the two regression lines reflects the difference in afterload of the two patient groups. As one expects, the two linear regression lines approach the same value at a regurgitant volume of 0 . Commonly used linear measures such as LV EDD and LV ESD showed a substantially worse correlation with regurgitant volume than volumetric measures such as LV EDVI or LV ESVI. These finding are consistent with previous reports that a linear measurement does not always accurately represent the actual volumetric changes of a 3dimensional structure such as the LV [25].

Many of the patients in this study were referred for CMR because the severity of the regurgitation could not be accurately determined by echocardiography. The clinical CMR reports included the regurgitant volume, LV dimensions, and LV volumes. Unfortunately, the LV volumes could not be used by the referring physician to determine the timing of surgical intervention because the AHA/ACC management guidelines only refer to linear dimensions. However, the fact that the volumetric measures correlated better to the regurgitant volume than corresponding linear measures suggests the possibility that volumetric measures may be more valuable than linear measures in assessing the response of the left ventricle to chronic MR or AR and in guiding the timing of surgical intervention. It is our hope that the volumetric correlates to the guideline dimensions which are listed in Table 2 will provide a foundation for the inclusion of volumetric data in future management guidelines.

\section{Study limitations}

Our data are retrospective in nature and only apply to patients with normal or mildly decreased left ventricular function and no other known cardiac disease. These data may not be applicable to patients with other concurrent cardiac diseases and/or LV dysfunction.

\section{Conclusion}

CMR is a robust technique for quantification of regurgitant volume in patients with AR or MR and preserved LV function. LV volumes show a stronger correlation with regurgitant volume than the linear dimensions recommended in the current management guidelines. These data suggest that LV volumes better reflect ventricular remodeling in patients with isolated mitral or aortic regurgitation.

\section{Abbreviations}

AR: aortic regurgitation; CMR: cardiac magnetic resonance; EDD: end-diastolic dimension; EDVI: end-diastolic volume index; ESD: end-systolic dimension; ESVI: end-systolic dimension index; LV: left ventricular; MR: mitral regurgitation; MRI: magnetic resonance imaging; RV: right ventricular.

\section{Competing interests}

The authors have no competing interests that relate to this study. Dr Steven Wolff is the owner of NeoSoft, LLC and NeoCoil, LLC.

\section{Authors' contributions}

SU and SDW designed the study, performed data analysis, and prepared the manuscript. AS performed statistical analysis. OS and CC performed image acquisition. SK, PN performed data collection. FC performed data analysis. All authors read and approved the final manuscript.

\section{Author Details}

'Division of Cardiology, Department of Medicine, St. Luke's-Roosevelt Hospital Center, Columbia University College of Physicians and Surgeons, 1111 Amsterdam Avenue, New York, NY 10025, USA and 2Advanced Cardiovascular Imaging, New York, NY, USA

Received: 13 January 2010 Accepted: 24 May 2010

Published: 24 May 2010

\section{References}

1. Bonow RO, Carabello BA, Chatterjee K, de Leon AC Jr, Faxon DP, Freed MD, Gaasch WH, Lytle BW, Nishimura RA, O'Gara PT, O'Rourke RA, Otto CM, Shah PM, Shanewise JS: 2008 focused update incorporated into the ACC/AHA 2006 guidelines for the management of patients with valvular heart disease: a report of the American College of Cardiology/ American Heart Association Task Force on Practice Guidelines (Writing Committee to revise the 1998 guidelines for the management of patients with valvular heart disease). Endorsed by the Society of Cardiovascular Anesthesiologists, Society for Cardiovascular Angiography and Interventions, and Society of Thoracic Surgeons. J Am Coll Cardiol 2008, 52(13):e1-142.

2. Rosenhek R, Rader F, Klaar U, Gabriel H, Krejc M, Kalbeck D, Schemper M, Maurer G, Baumgartner $\mathrm{H}$ : Outcome of watchful waiting in asymptomatic severe mitral regurgitation. Circulation 2006, 113(18):2238-2244.

3. Wittlinger T, Dzemali O, Bakhtiary F, Moritz A, Kleine P: Hemodynamic evaluation of aortic regurgitation by magnetic resonance imaging. Asian Cardiovasc Thorac Ann 2008, 16(4):278-283.

4. Dulce MC, Mostbeck GH, O'Sullivan M, Cheitlin M, Caputo GR, Higgins CB: Severity of aortic regurgitation: interstudy reproducibility of measurements with velocity-encoded cine MR imaging. Radiology 1992, 185(1):235-240.

5. Hundley WG, Li HF, Willard JE, Landau C, Lange RA, Meshack BM, Hillis LD, Peshock RM: Magnetic resonance imaging assessment of the severity of mitral regurgitation. Comparison with invasive techniques. Circulation 1995, 92(5):1151-1158.

6. Honda N, Machida K, Hashimoto M, Mamiya T, Takahashi T, Kamano T, Kashimada A, Inoue Y, Tanaka S, Yoshimoto N: Aortic regurgitation: 
quantitation with MR imaging velocity mapping. Radiology 1993, 186(1):189-194

7. Sondergaard L, Lindvig K, Hildebrandt P, Thomsen C, Stahlberg F, Joen T, Henriksen O: Quantification of aortic regurgitation by magnetic resonance velocity mapping. Am Heart J 1993, 125(4):1081-1090,

8. Bellenger NG, Burgess MI, Ray SG, Lahiri A, Coats AJ, Cleland JG, Pennell DJ: Comparison of left ventricular ejection fraction and volumes in heart failure by echocardiography, radionuclide ventriculography and cardiovascular magnetic resonance; are they interchangeable? Eur Heart J 2000, 21(16):1387-1396.

9. Epstein FH: MRI of left ventricular function. J Nucl Cardio/ 2007 14(5):729-744.

10. Grothues F, Moon JC, Bellenger NG, Smith GS, Klein HU, Pennell DJ: Interstudy reproducibility of right ventricular volumes, function, and mass with cardiovascular magnetic resonance. Am Heart $J 2004$ 147(2):218-223.

11. Schalla S, Nagel E, Lehmkuhl H, Klein C, Bornstedt A, Schnackenburg B, Schneider U, Fleck E: Comparison of magnetic resonance real-time imaging of left ventricular function with conventional magnetic resonance imaging and echocardiography. Am J Cardiol 2001, 87(1):95-99

12. Semelka RC, Tomei E, Wagner S, Mayo J, Caputo G, O'Sullivan M, Parmley WW, Chatterjee K, Wolfe C, Higgins CB: Interstudy reproducibility of dimensional and functional measurements between cine magnetic resonance studies in the morphologically abnormal left ventricle. Am Heart J 1990, 119(6):1367-1373.

13. Semelka RC, Tomei E, Wagner S, Mayo J, Kondo C, Suzuki J, Caputo GR, Higgins CB: Normal left ventricular dimensions and function: interstudy reproducibility of measurements with cine MR imaging. Radiology 1990, 174(3 Pt 1):763-768.

14. Rominger MB, Bachmann GF, Pabst W, Rau WS: Right ventricular volumes and ejection fraction with fast cine MR imaging in breathhold technique: applicability, normal values from 52 volunteers, and evaluation of 325 adult cardiac patients. J Magn Reson Imaging 1999, 10(6):908-918.

15. Chernobelsky A, Shubayev O, Comeau CR, Wolff SD: Baseline correction of phase contrast images improves quantification of blood flow in the great vessels. J Cardiovasc Magn Reson 2007, 9(4):681-685.

16. Grothues F, Smith GC, Moon JC, Bellenger NG, Collins P, Klein HU, Pennell $D J:$ Comparison of interstudy reproducibility of cardiovascular magnetic resonance with two-dimensional echocardiography in normal subjects and in patients with heart failure or left ventricular hypertrophy. Am J Cardiol 2002, 90(1):29-34

17. Stratemeier EJ, Thompson R, Brady TJ, Miller SW, Saini S, Wismer GL, Okada $R D$, Dinsmore RE: Ejection fraction determination by MR imaging: comparison with left ventricular angiography. Radiology 1986, 158(3):775-777.

18. Rajappan K, Livieratos L, Camici PG, Pennell DJ: Measurement of ventricular volumes and function: a comparison of gated PET and cardiovascular magnetic resonance. J NuCl Med 2002, 43(6):806-810.

19. Bogaert JDS: Clinical Cardiac MRI. 1st edition. Springer Verlag Inc; 2005.

20. Gelfand EV, Hughes S, Hauser TH, Yeon SB, Goepfert L, Kissinger KV, Rofsky NM, Manning WJ: Severity of mitral and aortic regurgitation as assessed by cardiovascular magnetic resonance: optimizing correlation with Doppler echocardiography. J Cardiovasc Magn Reson 2006, 8(3):503-507.

21. Fujita N, Chazouilleres AF, Hartiala JJ, O'Sullivan M, Heidenreich P, Kaplan JD, Sakuma H, Foster E, Caputo GR, Higgins CB: Quantification of mitral regurgitation by velocity-encoded cine nuclear magnetic resonance imaging. J Am Coll Cardiol 1994, 23(4):951-958.

22. Kizilbash AM, Hundley WG, Willett DL, Franco F, Peshock RM, Grayburn PA: Comparison of quantitative Doppler with magnetic resonance imaging for assessment of the severity of mitral regurgitation. Am $\lrcorner$ Cardiol 1998, 81(6):792-795.

23. Rossi A, Golia G, Gasparini G, Prioli MA, Anselmi M, Zardini P: Left atrial filling volume can be used to reliably estimate the regurgitant volume in mitral regurgitation. J Am Coll Cardiol 1999, 33(1):212-217.

24. Carabello BA: Aortic regurgitation. A lesion with similarities to both aortic stenosis and mitral regurgitation. Circulation 1990, 82(3):1051-1053.

25. Chuang ML, Hibberd MG, Salton CJ, Beaudin RA, Riley MF, Parker RA, Douglas PS, Manning WJ: Importance of imaging method over imaging modality in noninvasive determination of left ventricular volumes and ejection fraction: assessment by two- and three-dimensional echocardiography and magnetic resonance imaging. J Am Coll Cardiol 2000, 35(2):477-484

doi: 10.1186/1532-429X-12-32

Cite this article as: Uretsky et al., Quantification of left ventricular remodeling in response to isolated aortic or mitral regurgitation Journal of Cardiovascular Magnetic Resonance 2010, 12:32

\section{Submit your next manuscript to BioMed Central and take full advantage of:}

- Convenient online submission

- Thorough peer review

- No space constraints or color figure charges

- Immediate publication on acceptance

- Inclusion in PubMed, CAS, Scopus and Google Scholar

- Research which is freely available for redistribution
C Biomed Central 